\title{
SISTEM INFORMASI DOKUMEN SURAT MASUK DAN SURAT KELUAR PT INDUK HIK
}

\author{
Adriyan Ahsan', Dian Nur Sholihaningtias ${ }^{2}$ \\ Program Studi Teknik Informatika, Fakultas Teknik dan Ilmu Komputer, \\ Universitas Indraprasta PGRI \\ Jalan Raya Tengah No 80, Kelurahan Gedong, Pasar Rebo, Jakarta Timur \\ adriyan.ahsan@gmail.com ${ }^{1}$, dian.tyash@gmail.com ${ }^{2}$
}

\begin{abstract}
Abstrak
Tujuan dari penelitian adalah untuk Merancang dan membuat sistem informasi dokumen surat masuk dan surat keluar pada PT Induk HIK yang efektif dan efesien agar memperoleh data yang cepat dan akurat, penyimpanan data secara aman agar terhindar dari penyelewengan data, sehingga data yang diberikan relevan dan akurat, sekaligus aplikasi yang mudah digunakan sehingga pengguna dapat menjalankan aplikasi tanpa mengalami kesulitan sehingga data yang dimasukan akan mudah diolah. Penelitian ini dilakukan dengan menggunakan metode grounded research yaitu sebuah metode yang dilakukan berdasarkan fakta yang sebenarnya dan menggunakan analisa perbandingan dengan tujuan mengadakan generalisasi empiris, menetapkan konsep, membuktikan teori, mengembangkan teori, pengumpulan data dan analisa data dalam waktu yang bersamaan. Dari hasil pengujian yang telah dilakukan, penulis menyimpulkan bahwa sistem informasi dokumen surat masuk dan surat keluar ini dapat membantu produktifitas dalam kegiatan pengolahan data.
\end{abstract}

Kata Kunci : Dokumen, Surat Masuk, Surat Keluar

\begin{abstract}
The purpose of the research is to Design and create an information system of incoming and outgoing letter documents at PT Induk HIK that is effective and efficient in order to obtain fast and accurate data, secure data storage to avoid data misuse, so that the data provided is relevant and accurate, as well as applications that are easy to use so that users can run applications without experiencing difficulties so that the data entered will be easily processed. This research is done using the grounded research method which is a method that is done based on actual facts and uses comparative analysis with the aim of conducting empirical generalizations, establishing concepts, proving theories, developing theories, data collection and data analysis at the same time. From the results of the tests that have been done, the author concluded that this incoming letter and outgoing document information system can help productivity in data processing activities.
\end{abstract}

\section{Keywords: Document, Incoming Letters, Outgoing Letters}

\section{PENDAHULUAN}

Sistem adalah suatu jaringan prosedur yang dibuat menurut pola yang terpadu untuk melaksanakan kegiatan pokok perusahaan (Mulyadi, 2016). Informasi adalah hasil pemrosesan data yang diperoleh dari setiap elemen sistem agar menjadi bentuk yang mudah dipahami dan dibutuhkan oleh orang untuk menambah pemahaman terhadap fakta-fakta yang ada. Informasi dari setiap elemen akan berbeda satu sama lain sesuai kebutuhan masing-masing (Susilo, 2011). Era digital disebut pula era informasi, dimana informasi telah menjadi kebutuhan pokok dan komoditas baru. Era demikian dipicu teknologi informasi (TI) yang berperan mempercepat dan meningkatkan keakuratan dalam pencatatan dan pengolahan data menjadi suatu informasi. Setiap organisasi ataupun perusahaan pasti melakukan pengolahan data. Data tersebut dimaksudkan untuk menyediakan informasi yang akurat bagi manajemen perusahaan. data adalah fakta-fakta mentah kemudian dikelola sehingga menghasilkan informasi yang penting bagi sebuah perusahaaan atau organisasi (Indrajani, 2015). Sebagai objek penelitian penulis memilih PT. Induk HIK dimana perusahaan tersebut merupakan salah satu perusahaan yang bergerak di bidang perbankan syariah. Pemilihan objek ini mempertimbangkan bahwa ada beberapa kegiatan operasionalnya masih dilakukan secara manual, yaitu salah satunya adalah pendokumenan surat masuk dan surat keluar PT. Induk HIK. Berdasarkan identifikasi masalah yang ada pada PT Induk HIK diantaranya proses 
pendataan surat masuk dan surat keluar masih dilakukan secara manual, proses pemberian tata letak (penempatan surat di kabinet) masih dilakukan secara manual dan belum tertata, dokumen yang menumpuk sehingga memberikan masalah baru bagi perusahaan dan kesulitan dalam memonitor dokumen-dokumen tersebut. Tujuan dari sistem informasi ini dubiat diantaranya agar dokumen surat masuk dan surat keluar pada PT. Induk HIK efektif dan efesien, memperoleh data yang cepat dan akurat, serta penyimpanan data secara aman agar terhindar dari penyelewengan data, sehingga data yang diberikan relevan dan akurat.

\section{PENELITIAN RELEVAN}

Penelitian oleh (Kartikasari, 2011) yang berjudul sistem informasi pengelolaan surat masuk dan surat keluar pada unit perlaksanaan teknis taman kanak-kanak dan sekolah dasar kecamatan Pringkuku. Hasil penelitian tersebut adalah menghasilkan sistem informasi pengelolaan surat masuk dan surat keluar pada unit pelaksanaan teknis taman kanak - kanak dan sekolah dasar kecamatan pringkuku, yang efisien dan efektif, Selanjutnya penelitian oleh (Kusdinar, 2014) yang berjudul sistem informasi arsip surat masuk dan surat keluar pada bagian organisasi dan pemberdayaan aparatur daerah sekretariat kota Bandung. hasil penelitian tersebut adalah Aplikasi sudah cukup memadai dan bisa dimanfaatkan dengan baik, meskipun masih harus dikembang dan masih ada keterbatasan dalam menggunakan aplikasi.

\section{METODE PENELITIAN}

Dalam mengumpulkan data, keterangan dan rancangan program yang dibutuhkan untuk perancangan sistem komputerisasi berbasis komputer yang terdapat di PT Induk HIK, penulis menggunakan 2 (dua) metode yaitu.

1. Metode Lapangan (Field Research)

a. Observasi (pengamatan langsung)

Observasi adalah suatu cara pengumpulan data dengan mengadakan pengamatan langsung terhadap suatu obyek dalam suatu periode tertentu dan mengadakan pencatatan secara sistematis tentang hal-hal tertentu yang diamati.

b. Interview (wawancara)

Wawancara adalah suatu teknik pengumpulan data yang dilakukan dengan tanya jawab antara interviewer (penanya) dengan responden (penjawab).

2. Studi Pustaka.

Pengumpulan data dan informasi yang penulis lakukan untuk perancangan sistem informasi ini adalah dengan cara.

a. Mempelajari buku-buku literatur mengenai menganalisis dan mendesain sebuah sistem.

b. Mempelajari sistem dari aplikasi sistem komputerisasi kantor lain yang serupa dengan aplikasi yang akan dibuat.

c. Mempelajari buku-buku Pemrograman Java dan Database MySQL untuk mengiterasikannya.

\section{HASIL DAN PEMBAHASAN \\ Analisa Permasalahan}

Dalam pelaksanaan kegiatan pendokumenan surat masuk dan keluar pada PT Induk HIK terdapat permasalahan-permasalahan yang dihadapi, diantaranya, proses pendataan surat masuk dan surat keluar masih dilakukan secara manual, penumpukan dokumen sehingga sulit sekali untuk dicari ketika dibutuhkan pada kemudian hari. dokumen yang semakin lama semakin menumpuk. hilang nya dokumen, dan tidak memiliki backup digital.

\section{Alternatif Penyelesaian Masalah}

Dari permasalahan yang muncul ditemukan solusi pemecahan masalah untuk menangani permasalahan tersebut. Berikut adalah hasil terhadap solusi pemecahan masalah daiantaranya, pengembangan sistem informasi dokumen surat masuk dan surat keluar berbasis java ini dapat membantu pendataan surat masuk maupun keluar dengan penomoran yang sudah terotomatisasi, pengembangan sistem informasi dokumen surat masuk dan surat keluar berbasis java ini dapat membantu mempercepat proses pencarian data surat masuk dan data surat keluar karena data tersebut sudah tersimpan dalam database, Pengembangan sistem informasi dokumen surat masuk 
dan surat keluar berbasis java ini dapat menyimpan surat masuk maupun surat keluar secara softcopy dengan mengupload hasil scan dokumen surat masuk dan surat keluar sehingga dapat mencegah penumpukan surat dan hilang nya surat di kemudian hari.

\section{Use Case Diagram}

Use case diagram merupakan suatu permodelan untuk mendeskripsikan kebutuhan sistem terutama aktor yang akan menggunakan sistem, sehingga segala persyaratan sistem yang baik dapat tergambarkan. Dengan teknik use case, fungsi dapat digambarkan apa saja yang ada di dalam sistem dan siapa saja user yang berhak menggunakan sistem tersebut. Use case diagram pada sistem informasi dokumen surat masuk dan surat keluar pada PT Induk Harta Insan Karimah.

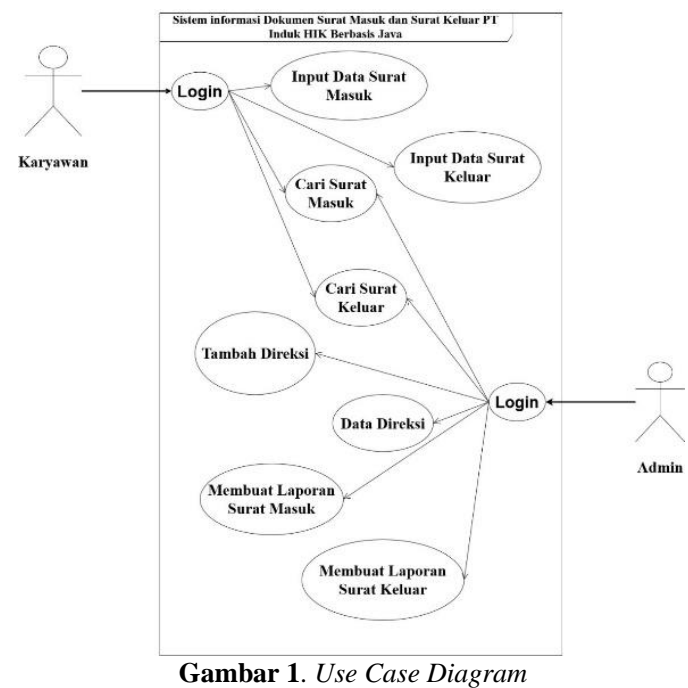

\section{Sequence Diagram}

Sequence diagram adalah suatu diagram yang menggambarkan interaksi antar obyek dan mengindikasikan komunikasi diantara obyek-obyek tersebut.
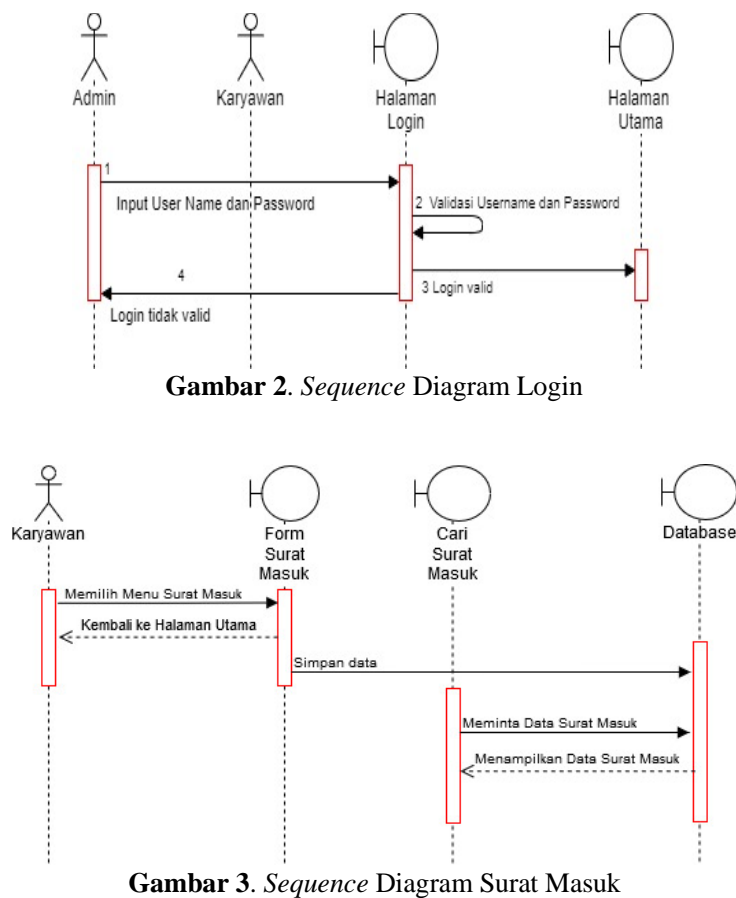
Jurnal Riset dan Aplikasi Mahasiswa Infarmatika (JRAMI)

Vol 03 № 01 Tahun 2022

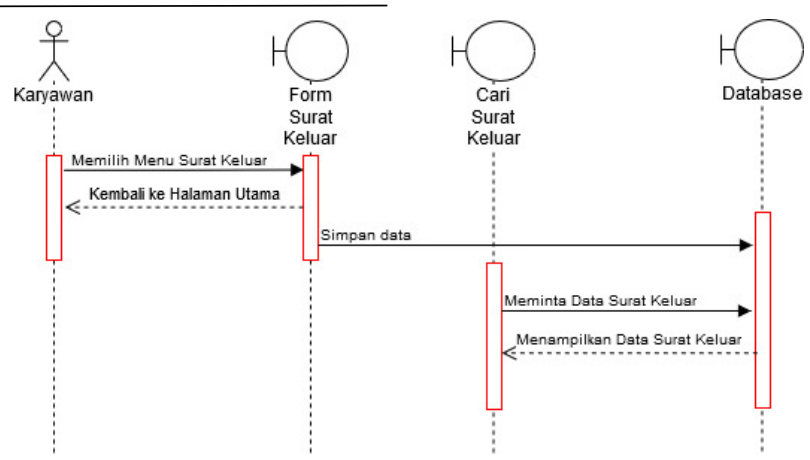

Gambar 4. Sequence Diagram Surat Keluar

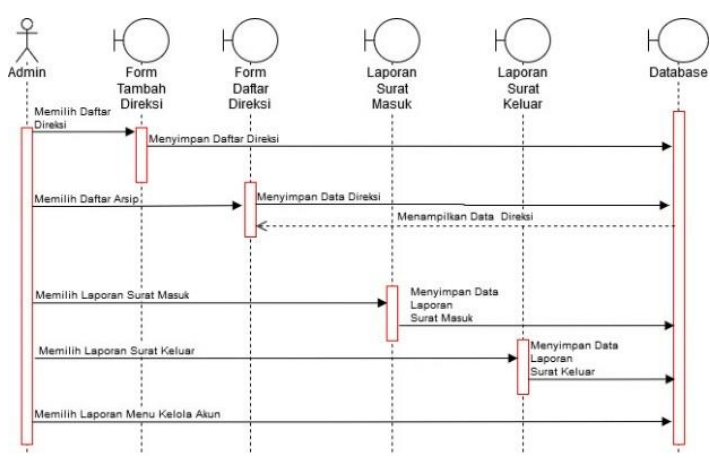

Gambar 5. Sequence Diagram Admin

\section{Logical Relational Structure}

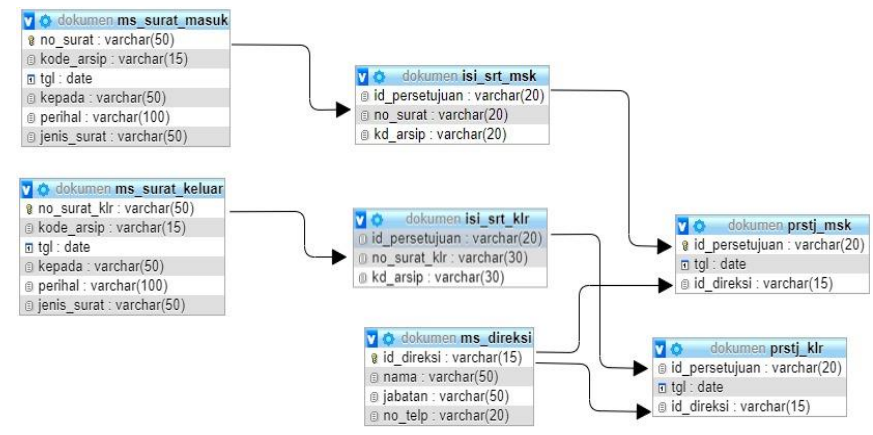

Gambar 6. Logical Relational Structure

Tampilan layar

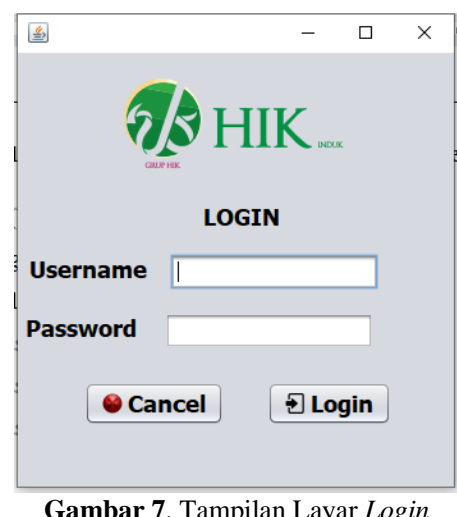

Pada Gambar 8 merupakan gambar tampilan login, user dapat menginputkan username dan password untuk dapat mengakses aplikasi ini. 


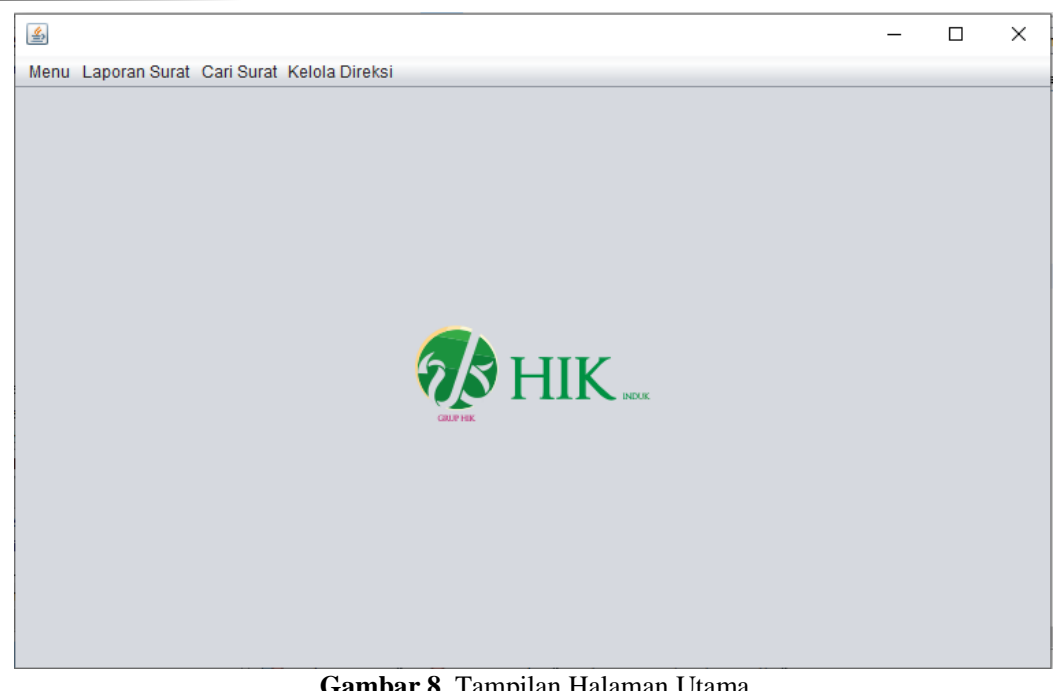

Pada Gambar 8 merupakan tampilan halaman utama, terdapat beberapa menu dalam tampilan ini seperti menu, laporan surat, cari surat dan kelola redaksi.

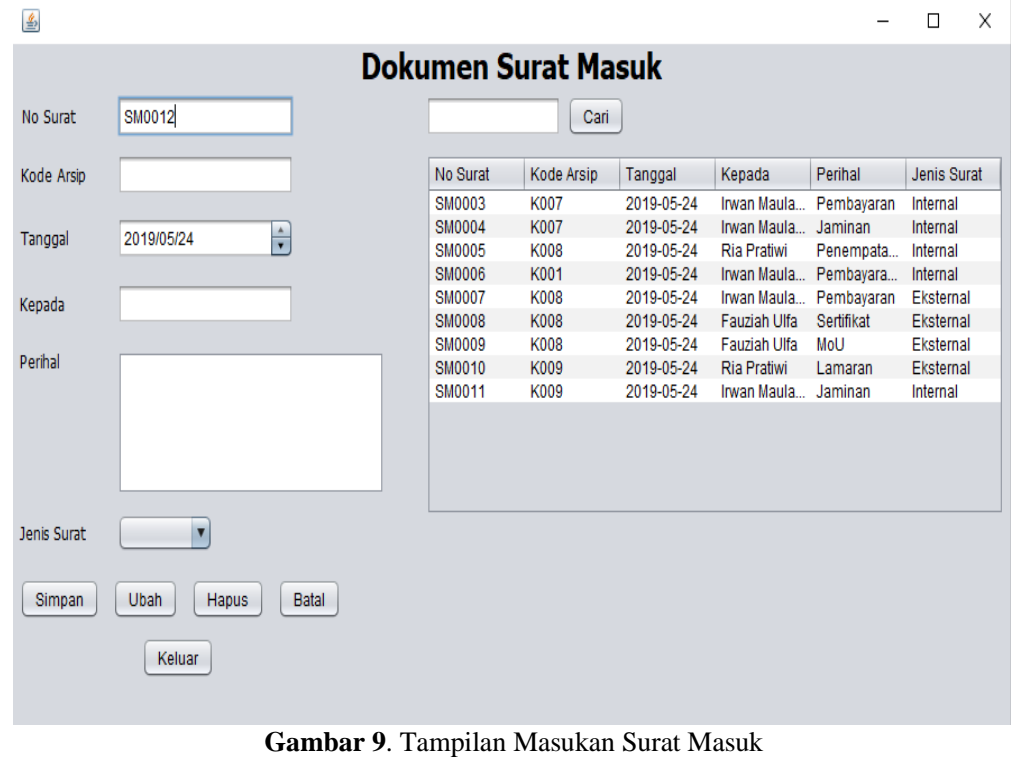

Pada Gambar 9 merupakan tampilan form dokumen surat masuk, user dapat menginputkan no surat, kode arsip, tanggal, kepada, perihal serta jenis surat. Terdapat beberapa tombol button pada form tersebut seperti simpan, ubah, hapus, batal dan keluar. 


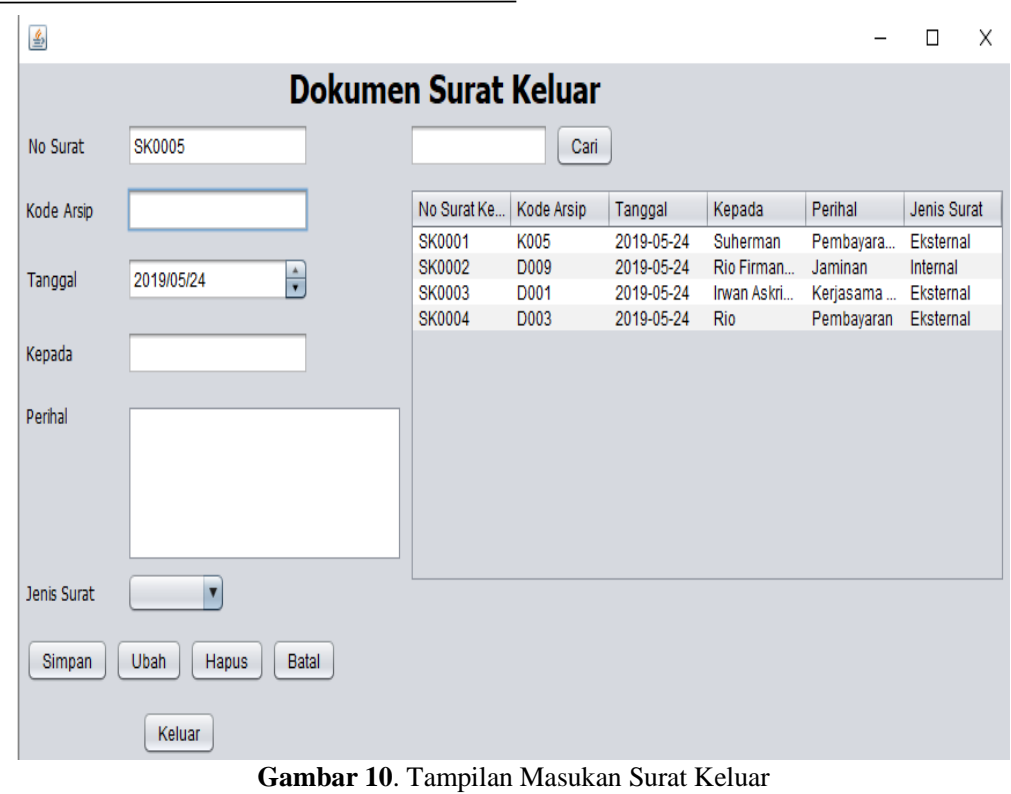

Pada Gambar 10 merupakan tampilan form dokumen surat keluar, user dapat menginputkan no surat, kode arsip, tanggal, kepada, perihal serta jenis surat. Terdapat beberapa tombol button pada form tersebut seperti simpan, ubah, hapus, batal dan keluar.

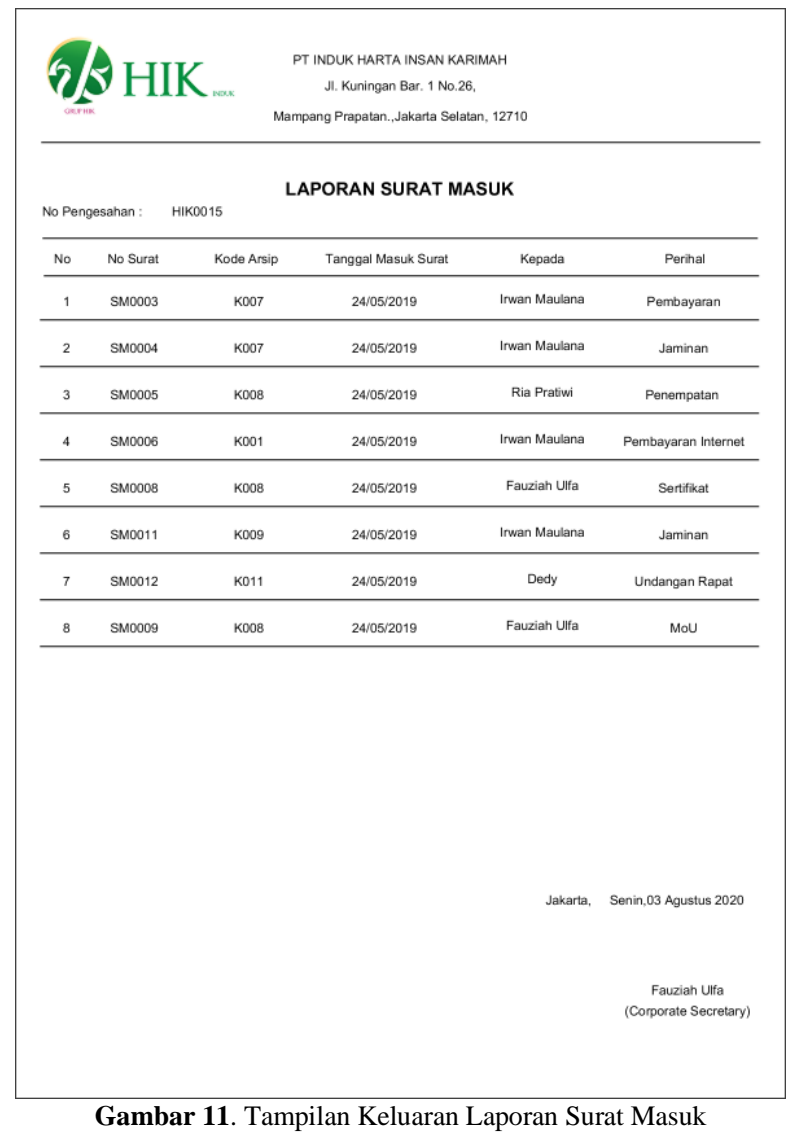

Pada Gambar 11 merupakan tampilan laporan surat masuk 


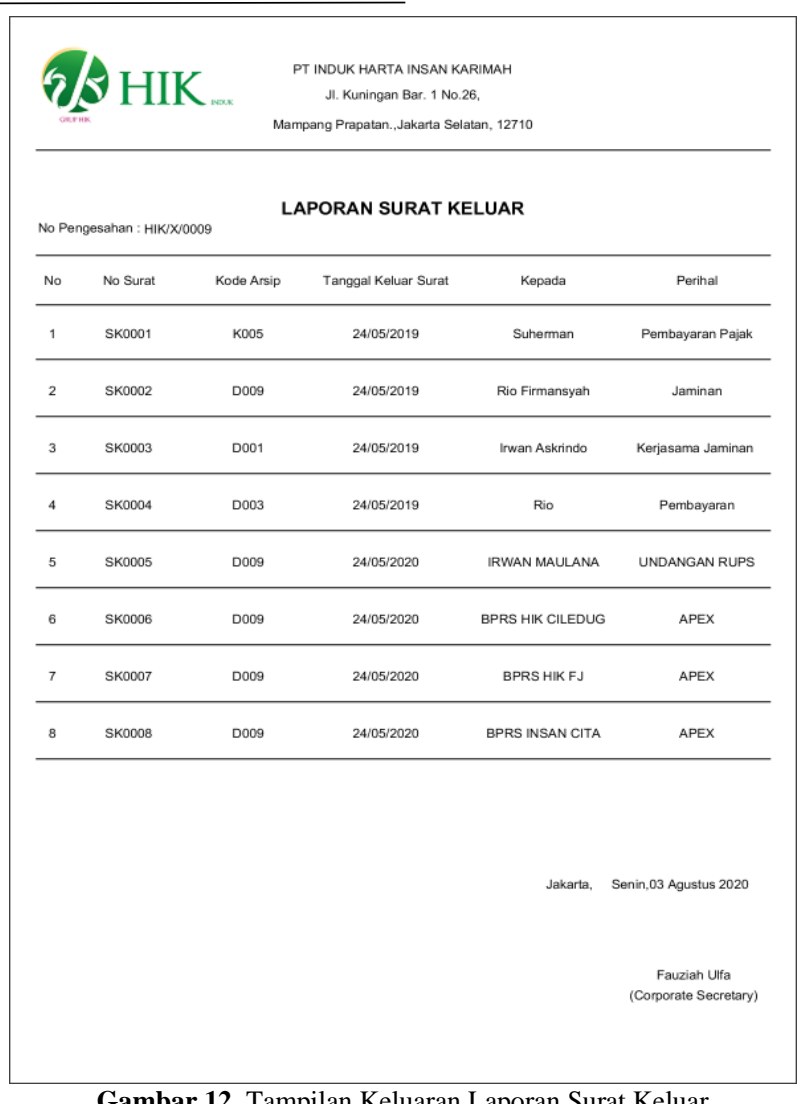

Pada Gambar 12 merupakan tampilan laporan surat keluar

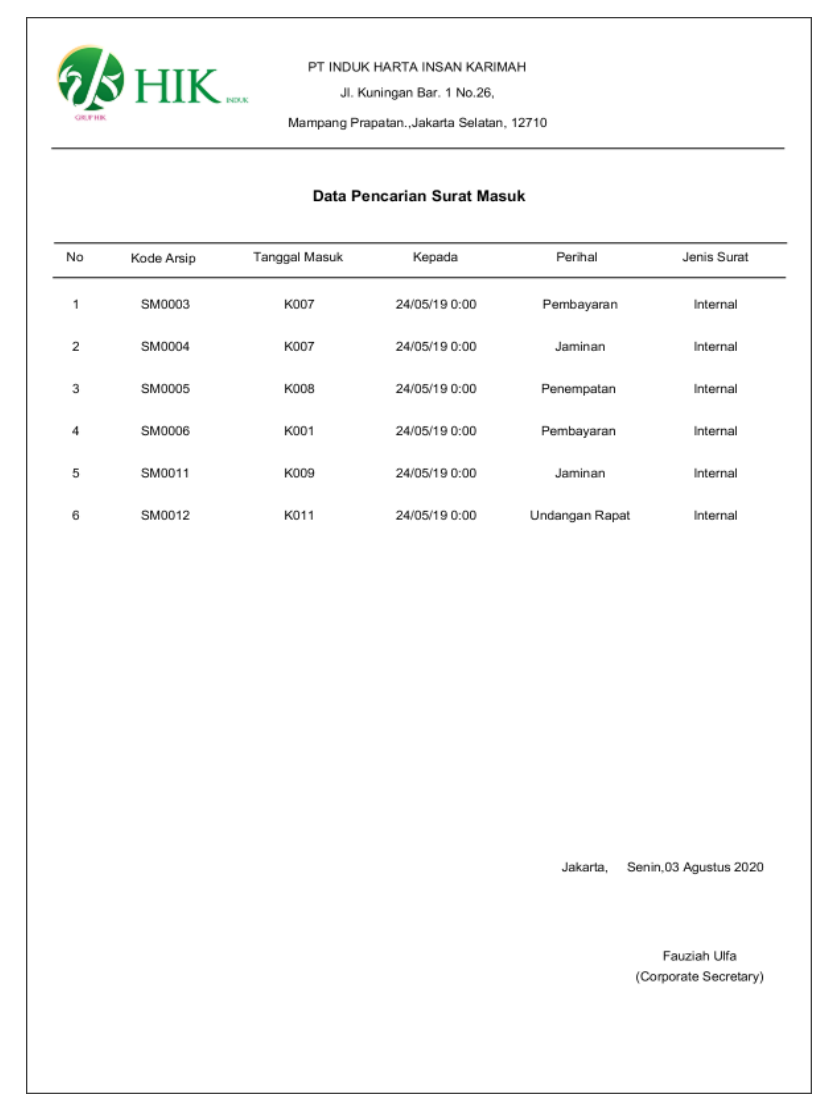

Gambar 13. Tampilan Keluaran Laporan Data Surat Masuk

Pada Gambar 13 merupakan tampilan laporan data surat masuk 


\section{SIMPULAN}

Peralihan sistem pendataan secara manual ke sistem yang terkomputerisasi pada PT Induk Harta Insan Karimah menjadikan proses pendokumenanan surat masuk dan surat keluar tidak lagi dilakukan secara manual tetapi dengan menggunakan media berupa komputer. Dan dengan adanya sistem ini diharapkan akan mempermudah kegiatan pendokumenan surat masuk dan surat keluar PT Induk Harta Insan Karimah dan menambah keefektifan karyawan dalam bekerja.

\section{DAFTAR PUSTAKA}

Indrajani. (2015). Database Design. Jakarta: PT Elex Media Komputindo.

Kartikasari, S. W. (2011). Sistem Informasi Pengelolaan Surat Masuk dan Surat Keluar Pada Unit Perlaksanaan Teknis Taman Kanak-Kanak dan Sekolah Dasar Kecamatan Pringkuku. Jakarta: Universitas Surakarta.

Kusdinar, I. C. (2014). Sistem Informasi Arsip Surat Masuk Dan Surat Keluar Pada Bagian Organisasi Dan Pemberdayaan Aparatur Daerah Sekretariat Kota Bandung. Bandung: Universitas Komputer Indonesia.

Mulyadi. (2016). Sistem Akuntansi. Dalam Sistem Akuntansi (hal. 4). Jakarta: Salemba Empat.

Oetomo. (2011). Dalam E. Susilo, Sistem Penjualan Online Berbasis Web dengan CMS Koma pada Toko Win Komputer di Kota Semarang. Semarang: Polines. Anastasia, D., \& Lilis, S. (2011). Dalam Sistem Informasi Akuntansi (hal. 3). Yogyakarta: Andi.

Arief, M. (2011). Pemograman Web Dinamis Menggunakan PHP dan MySQL. Yogyakarta: Andi.

Lidia, L. (2011). Perancangan Sistem Aplikasi Kepegawaian Pada Badan Pemberdayaan Masyarakat dan Pemerintahan Desa (BPMPD) Kab. Bogor. Jakarta: Universita Indraprasta.

Mulyadi. (2016). Sistem Akuntansi. Dalam Sistem Akuntansi (hal. 4). Jakarta: Salemba Empat.

Mutiani, \& Tri, I. (2011). Indonesian Jurnal on Computer Science-Speed (IJCSS). Sistem Informasi Pembuatan Surat Pemesanan Obat Berbasis Sms Gateway Pada Pt. Sehat Bersama Sejahtera.

Nugroho, A. (2011). Perancangan dan Implementasi Sistem Basis Data. Yogyakarta: Andi.

Pabokory, F. N., Astuti, I. F., \& Kridalaksana, A. H. (2015). informatika Mulawarman. Implementasi Kriptografi Pengamanan Datapada Pesan Teks, Isi File Dokumen, Dan File Dokumenmenggunakan Algoritma Advanced Encryptionstandard. Susilo, E. (2011). Dalam Oetomo, Sistem Penjualan Online Berbasis Web dengan CMS Koma pada Toko Win Komputer di Kota Semarang. Semarang: Polines.

Widodo, B. P. (2014). Dalam Pengurusan Surat. Jakarta: Universitas Terbuka.

Wongso, F. (2015). Jurnal Ilmiah Ekonomi dan Bisnis. Perancangan Sistem Informasi Penjualan Berbasis Java. 